метров приготовления бисквита на основе тритикалевой муки // Хлебопродукты. - 2010. - № 7. - С. 31-33.

6. Тугуш А.Р., Садыгова М.К., Белова М.В., Рысмухамбетова Г.Е. Разработка технологических решений использования продуктов переработки из корнеплодов в производстве песочного печенья // Успехи современной науки и образования. - 2017. T. 6. - № 3. - С. 214-218.

Тугуш Асия Рафаильевна, магистрант, Саратовский государственный аграрный университет имени Н.И. Вавилова. Россия.

Каневская Ирина Юрьевна, канд. с.-х. наук, доцент кафедры «Математика и математическое моделирование», Саратовский государственный аграрный университет имени Н.И. Вавилова. Россия.

Садыгова Мадина Карипулловна, $\partial-p$ техн. наук, проф. кафедры «Технологии продуктов питания», Саратовский государственный аграрный университет имени Н.И. Вавилова. Россия.

Кириллова Татьяна Валерьяновна, канд. техн. наук. доцент кафедры «Математика и математическое моделирование», Саратовский государственный аграрный университет имени Н.И. Вавилова. Россия.

Контарева Дарья Дмитриевна, студентка, Саратовский государственный аграрный университет имени Н.И. Вавилова. Россия.

410012, г. Саратов, Театральная пл., 1.

Тел.: (8452) 23-32-92.

Ключевые слова: овощной порошок; песочное печенье; деформация объекта; намокаемость; оптимизация; статистические модели; индекс корреляиии; экономическая эффективность.

\title{
USAGE OF THE METHOD OF REGRESSION ANALYSIS TO OPTIMIZE THE AD-MIXTURES IN THE RECIPE OF SHORTBREAD
}

Tugush Asia Rafailyevna, Magistrandt, Saratov State Agrarian University named after N. I. Vavilov. Russia.

Kanevskaya Irina Yurievna, Candidate of Agricultural Sciences, Associate Professor of the chair "Mathematics and Mathematical Modeling”, Saratov State Agrarian University named after N.I. Vavilov. Russia.

Sadygova Madina Karipullovna, Doctor of Technical Sciences, Professor of the chair "Technologies of Food Products", Saratov State Agrarian University named after N.I. Vavi-lov. Russia.

Kirillova Tatyana Valeryanovna, Candidate of Technical Sciences, Associate Professor of the chair "Mathematics and Mathematical Modeling”, Saratov State Agrarian University named after N. I. Vavilov. Russia.

Kontareva Darya Dmitrievna, 4th course student of the direction of training 19.03.02 - "Food Products from Plant Material", Saratov State Agrarian University named after N. I. Vavilov. Russia.

Keywords: vegetable powder; shortbread; object deformation; soakage; optimization; sta-tistical models; correlation index; economic efficiency.

The economic efficiency of shortbread production is presented and proved. The cal-culations of cost per unit of output are given; the profitability from sales is shown. The non-linear multivariate statistical models to quantify the influence of the dosage of vegetable powder and sugar on physico-chemical parameters and rheological characteristics of fin-ished products are developed. The input parameters are number of vegetable powder and sugar. The adjustable parameters of the model are mass fraction of moisture, soakage and deformation of the object. It is proved that the manipulation of vegetable powder volume has an influence on the physico-chemical parameters and rheological characteristics of shortbread. There is defined the optimal amount of vegetable powder 15 per cent while reducing the amount of sugar by 10 per cent. It gives the opportunity to get the product of a dietary purpose.

\section{ПРОГРАММНО-ЦЕЛЕВАЯ ПОДДЕРЖКА КЛАСТЕРНЫХ ИНИЦИАТИВ В АПК РЕГИОНА}

\section{ЧЕТОШНИКОВА Любовь Александровна, Новороссийский филиал Финансового университе- та при Правительстве РФ}

Статья посвящена исследованию программно-иелевой поддержке кластерных инициатив в одном из приоритетного направления развития специализации экономики Краснодарского края - АПК. Показано, что возможности развития АПК региона определяются его мощным агропромышленным потенциалом. Существенный резерв активизации инвестиционной деятельности заложен в кластерных образованиях. Выявлены проблемы развития формирующихся территориально-производственных кластеров в сфере АПК и определены направления развития процессов кластеризации.

Введение. Интерес к кластерам как новой единице пространственной и экономической структуры обусловлен общепризнанным фактом положительного влияния процессов кластеризации на конкурентоспособность. Практически все государства мира взяли курс на целенаправленное формирование кластеров в рамках промышленной, аграрной, инновационной (научно-технической), инвестицион- ной политики и политики поддержки малого и среднего бизнеса [1]. Говоря об отечественных кластерах в сельскохозяйственной сфере, нельзя сбрасывать со счетов и такие факторы, как эффективное развитие подотраслей АПК с учетом технологических особенностей и проблем сбытового характера, а также конструктивное решение социально-экономических задач на региональном уровне. 
Методика исследований. Проблемы создания и функционирования кластеров являются темой многочисленных на сегодняшний день отечественных научных исследований. Анализ литературных источников позволяет утверждать, что в настоящее время среди ученых не сложилось единого мнения по таким важнейшим вопросам, как атрибутивные признаки кластера, программы их «искусственного» выращивания, качество институциональной среды кластеров, необходимость и эффективность их функционирования в российской экономической среде $[1,4,9]$.

Теоретическую и методологическую основу исследования составили не только вышеназванные труды ученых, но и нормативно-правовые акты - Распоряжения Правительства РФ, федеральные и региональные законы, а также программы социально-экономического развития. Методологической основой исследования является системно-синтетический подход. При этом синтез заключался в учете трех позиций исследования выбранной проблематики - отраслевой, в первую очередь технологической, институциональной и географической. Так, конкретной целью статьи был анализ проблем и перспектив агропромышленного комплекса Краснодарского края, существенный резерв развития которого заложен в кластерных образованиях.

Результаты исследований. Надежность и уровень институциональной системы региона обеспечивает достаточно высокое качество взаимоотношений с федеральным центром, эффективную реализацию проектов, в т.ч. числе международных, и высокую привлекательность для бизнеса. Благодаря государственному регулированию и поддержке отраслей экономики региона повышается привлекательность прямых инвестиций. Так, например, «инвесторы стали иначе относиться к аграрной индустрии в связи с ростом мировых цен на продовольствие и повышением значимости сельского хозяйства в целом» $[8$, с. 98].

В Стратегии социально-экономического развития Южного федерального округа на период до 2020 года на территории Краснодарского края выделено 6 зон опережающего роста [7]. При этом в 4 из них - Восточной Кубанской, Юго-Западной Черноморской, Северо-Западной Азовской, Северной Кубанской - выделен как приоритетное направление специализации агропромышленный комплекс (сельское хозяйство). Точками экономического роста, которые смогут обеспечить приток новых инвестиций в развитие агропромышленного комплекса Краснодарского края, в ближайшее десятилетие станут территориальные кластеры: агропищевой, винодельческий и рыбоперерабатывающий.

Вместе с тем, в настоящее время следует выделить следующие основные проблемы и ог- раничивающие факторы развития формирующихся территориальных кластеров. Так, в сфере развития агропищевого кластера существующая в регионе сельскохозяйственная сырьевая база не обеспечивает полную загрузку предприятий пищевой и перерабатывающей промышленности (в среднем загрузка предприятий составляет от $20 \%$ до $60 \%$ процентов). В связи с данным обстоятельством, требуется увеличение объемов производства на территории региона всех видов сельскохозяйственной продукции, в особенности продукции животноводства. Более того отмечается недостаточный уровень развития региональной инфраструктуры рынка сельскохозяйственной продукции, что обусловлено нехваткой современных овощехранилищ, фруктохранилищ, логистических комплексов, а также торгово-закупочных и заготовительных центров, обеспечивающих координацию производителей сельскохозяйственной продукции с торговыми сетями в части востребованных рынком видов продукции и сроков ее поставки. Отмечается недостаточная глубина промышленной переработки продукции животноводства и растениеводства, недостаточное количество тепличных комплексов, обеспечивающих круглогодичные поставки сельскохозяйственной продукции.

В то же время получают развитие инвестиционные проекты, направленные на тепличное производство продукции растениеводства. Так, планируется строительство четвертой и пятой очереди теплиц в Динском районе общей площадью 27 га. Общая площадь защищенного грунта в крупных сельхозорганизациях составит 198 га, что позволит получать более 80 тыс. т высококачественной овощной продукции. В 2016 г. осуществлен ввод в эксплуатацию комплекса по переработке молока с производственной мощностью 18 тыс. т. молока и 864 т говядины в год в Калининском районе, а также строительство калибровочно-перерабатывающего комплекса мощностью 5 тыс. т семян подсолнечника в год в Белоглинском районе. В сфере переработки сельскохозяйственной продукции и производства продуктов питания в рассматриваемой перспективе планируется реализация комплекса инвестиционных проектов. В 2018 г. планируется завершить реализацию инвестиционного проекта по модернизации и реконструкции сахарного завода в Усть-Лабинском районе мощностью 75 тыс. т сахара в год.

Активное развитие винодельческого кластера в регионе ограничивается целым комплексом взаимосвязанных проблем, требующих разрешения: например, недостаточная обеспеченность винодельческих предприятий сырьем (виноградом), произведенным на территории Краснодарского края. Собственное сырье для виноделия в регионе покрывает только около 40 \% спроса. 
Для обеспечения увеличения объемов производства недостающие объемы виноматериалов ввозятся из стран Европы. Наращивание сырьевого потенциала сдерживается нехваткой свободных виноградопригодных земель, которые можно было бы вовлечь в производство качественных сортов винограда, потребляемых винодельческой промышленностью. Значительная часть этих земельных ресурсов находится в фонде перераспределения края, а также в частной собственности и не вовлечена в производство винограда. Кроме того, по мнению экспертов, потенциал края в виноградопригодных землях не ограничивается лишь юго-западными территориями региона. Значительный резерв виноградопригодных земель, которые также не вовлечены в производство винограда, имеется на территории предгорных районов края - Крымском, Абинском и Северском.

Наблюдается снижение площадей виноградников более быстрыми темпами, чем освоение виноградопригодных земель. Это связано с низкой рентабельностью, а в отдельных случаях и убыточностью деятельности ряда виноградарских хозяйств. На данную ситуацию, с одной стороны, влияет ввоз дешевых импортных виноматериалов, а с другой - высокая себестоимость выращивания винограда. Как следствие, не удается достигнуть конкурентоспособности отрасли виноделия края по отношению к зарубежным производителям. Отечественное производство вина уступает по такому параметру, как соотношение цена-качество. Вместе с тем в направлении снижения цены на производимое вино предприятия сталкиваются с невозможностью снижения отдельных непроизводительных затрат из-за особенностей производственного процесса.

Также следует констатировать, что отдельные положения Федерального закона от 22 ноября 1995 г. № 171 - Ф3 «О государственном регулировании производства и оборота этилового спирта, алкогольной и спиртосодержащей продукции и об ограничении потребления (распития) алкогольной продукции» не стимулируют развитие виноградарства и высококачественного виноделия, неблагоприятно воздействуют на финансовое состояние предприятий отрасли, а также являются препятствием для вхождения в отрасль предприятий малого и среднего бизнеса [5]. В частности, данным законом к производству натурального вина предъявляются такие же требования, как и к производству напитков с использованием этилового спирта. В результате значительные финансовые ресурсы предприятий отвлекаются на лицензирование, закупку оборудования по контролю за оборотом продукции, внесение залога при получении акцизной марки в размере 100 \% от стоимости марки.
Нельзя не выделить еще одну проблему отрасли виноделия в регионе - отсутствие качественной системы дистрибуции, маркетинга и продвижения продукции виноделия Краснодарского края за его пределами.

В сфере развития рыбоперерабатывающего кластера выделяются следующие проблемы:

отсутствие портовых мощностей с пунктами приема и первичной обработки водных биологических ресурсов;

высокий уровень износа и технологическое отставание судов и плавбаз, осуществляющих рыбный промысел в Азовском и Черном морях;

отсутствие репродукционного центра, способного производить качественный, высокопродуктивный рыбопосадочный материал в необходимом количестве;

отсутствие специально подготовленных инвестиционных площадок «под ключ» для проектов, связанных с созданием новых предприятий по глубокой переработке рыбных ресурсов;

ухудшающаяся экологическая ситуация в основных местах нерестилищ ценных рыб в связи с отсутствием мелиоративных работ в лиманах (последний раз масштабная мелиорация Кубанских лиманов проводилась в 30-е гг. прошлого столетия);

сокращение промысловых запасов водных биологических ресурсов Азово-Черноморского бассейна.

И, конечно, общая для развития формирующихся интеграционных территориальных комплексов проблема, заключающаяся в совершенствовании системы кредитования производителей сельскохозяйственной продукции. При этом, «...в экономике края функционирует насыщенная инфраструктура стимулирования капиталовложений» [11, с. 98].

В Программе социально-экономического развития Краснодарского края на 2013-2017 гг. зафиксировано сокращение долгосрочных краевых и ведомственных программ развития различных отраслей экономики региона [6]. Если в 2013г. финансировалось из различных источников 93 программы, то к 2017 г. планируется финансирование только 11 программ, из них 9 программ, относящихся к сфере АПК. Большая часть ведомственных целевых программ уже реализованы в 2013-2015 гг., в 2016-2017 гг. продолжалось финансирования 3-х долгосрочных целевых программ: «Развитие сельского хозяйства и регулирование рынков сельскохозяйственной продукции, сырья и продовольствия в Краснодарском крае», «Развитие мясного животноводства в Краснодарском крае», «Развитие мелиорации сельскохозяйственных земель в Краснодарском крае».

Анализ динамики объемов финансирования программных мероприятий в АПК показал, что при сокращении общего объема финансирования 


\begin{tabular}{|c|c|c|c|c|c|c|}
\hline Показатель & 2011 г. & 2012 г. & 2013 г. & 2014 г. & 2015 г. & 2016 г. \\
\hline $\begin{array}{l}\text { 1. Наличие основных фондов, на конец } \\
\text { года, млн руб. }\end{array}$ & 206138 & 223435 & 240146 & 248901 & 277456 & 308454 \\
\hline $\begin{array}{l}\text { 2. Ввод в действие основных фондов, } \\
\text { млн руб. }\end{array}$ & 22075 & 23801 & 20787 & 22814 & 25150 & 30835 \\
\hline $\begin{array}{l}\text { 3. Степень износа основных фондов, на } \\
\text { конец года, \% }\end{array}$ & 41,5 & 42,4 & 43,4 & 46,7 & 45,0 & $\ldots$ \\
\hline $\begin{array}{l}\text { 4. Индекс производства продукции сель- } \\
\text { ского хозяйства, \% к предыдущему году }\end{array}$ & 110,1 & 89,3 & 107,6 & 102,0 & 103,3 & 110,0 \\
\hline $\begin{array}{l}\text { 5. Индекс цен товаропроизводителей сель- } \\
\text { скохозяйственной продукции, \% к преды- } \\
\text { дущему году }\end{array}$ & 120,5 & 97,8 & 111,3 & 104,6 & 118,1 & 101,1 \\
\hline $\begin{array}{l}\text { 6. Среднесписочная численность работни- } \\
\text { ков, тыс. чел. }\end{array}$ & 382,9 & 383,8 & 377,8 & 373,4 & 374,5 & $\ldots$ \\
\hline $\begin{array}{l}\text { 7. Среднемесячная номинальная начислен- } \\
\text { ная зарплата, руб. }\end{array}$ & 15109 & 16637 & 18296 & 20031 & 22432 & 25511 \\
\hline $\begin{array}{l}\text { 8. Сальдированный финансовый результат } \\
\text { (прибыль минус убыток) организаций, } \\
\text { млн руб. }\end{array}$ & 14546 & 13556 & 12461 & 21258 & 38974 & 42628 \\
\hline $\begin{array}{l}\text { 9. Рентабельность проданных товаров, } \\
\text { продукции (работ, услуг) в растениеводс- } \\
\text { тве, \% }\end{array}$ & 24,5 & 21,8 & 22,3 & 32,6 & 50,1 & $\ldots$ \\
\hline $\begin{array}{l}\text { 10. Рентабельность проданной продукции, } \\
\text { (работ, услуг) в животноводстве, \% }\end{array}$ & 9,2 & 7,7 & 8,5 & 19,7 & 27,1 & $\ldots$ \\
\hline 11. Удельный вес убыточных организаций, \% & 20,5 & 23,4 & 21,7 & 17,4 & 14,1 & $\ldots$ \\
\hline 12. Сумма убытка организаций, млн руб. & 3516 & 4428 & 8531 & 8362 & 5570 & 1653 \\
\hline
\end{tabular}

программных мероприятий, в сфере АПК финансирование незначительно увеличивается: с 10,4 млн руб. в 2013 г. до 13,0 млн руб. в 2017 г. [10]. Анализ источников финансирования программ в АПК показал, что при незначительном увеличении финансирования из федерального бюджета и сокращении финансирования из краевого бюджета, главную роль играют внебюджетные источники финансирования. Однако большое влияние на активизацию инвестиционной деятельности в регионе оказывают бюджетные инвестиции из консолидированного федерального бюджета [3]. «Бюджетные инвестиции создают необходимые инфраструктурные условия для притока частных вложений в развитие регионов и позволяют осуществлять инвестиционную деятельность в рамках механизма государственно-частного партнерства» [2, с. 11]. 
Рассматривая условия для формирования инвестиционной деятельности в сельском хозяйстве региона, представленные в таблице, отметим динамику повышения рентабельности производимой сельскохозяйственной продукции [10].

Анализ данных таблицы позволяет сделать вывод об устойчивой динамике большинства показателей, характеризующих сложившиеся условия для формирования инвестиционной деятельности в сельском хозяйстве региона.

Заключение. Программно-целевой подход поддержки ведения отдельных видов бизнеса оказывает положительное влияние на АПК края. По мнению автора, в целях формирования инновационной экономики региона необходима, в первую очередь, государственная поддержка в сфере привлечения частного капитала для реализации кластерных проектов. Особенно важна со стороны государства поддержка партнерских отношений хозяйствующих сторон в составе кластерных образований. В этом направлении требует совершенствования законодательная база, регулирующая взаимоотношения хозяйствующих субъектов. Также необходима организация четкой работы бизнес-инкубаторов, технопарков и других институтов развития. Регионы с отлаженной системой институтов обладают рядом преимуществ, заключающихся в возможности снижения неопределенности и риска, сокращения издержек, ускорения оборота капитала и улучшения инвестиционного климата. Осуществление мероприятий в данных направлениях будет способствовать эффективной реализации потенциала развития экономики региона в целом и сферы АПК, в частности.

\section{СПИСОК ЛИТЕРАТУРЫ}

1. Александрова Л.А., Матвеева О.В. Институциональный подход в кластерных исследованиях // Аграрный научный журнал. - 2014. - № 10. - С. 65-69.

2. Климанов В.В., Москвитина Н.А. Роль государства в регулировании инвестиционной деятельности на региональном уровне // Региональная экономика: теория и практика. - 2015. - № 4. - С. 2-15.

3. Матвеева Л.Г., Никитаева А.Ю., Чернова О.А. Перспективы и потенциал развития регионов юга России в условиях антироссийских экономических санкций // Региональная экономика. - 2015. - № 17. C. $2-12$.

4. Мизанбекова С., Богомолова И., Богомолов А. Современные тенденции кластеризации зернопродуктового комплекса Казахстана // Международный сельскохозяйственный журнал. - 2016. - № 2. C. $32-34$.

5. О государственном регулировании производства и оборота этилового спирта, алкогольной и спиртосодержащей продукции и об ограничении потребления (распития) алкогольной продукции: Федеральный закон от 22 ноября 1995 года № 171. - Режим доступа: http://base.garant.ru/10105489/.

6. О программе социально-экономического развития Краснодарского края на 2013-2017 гг.: Закон Краснодарского края. - Режим доступа: http:// economy.krasnodar.ru/strategic-planning/the-programof-development-of-krasnodar-region/files/soc-ekon razv 2013-17.PDF.

7. Об утверждении Стратегии социально-экономического развития Южного федерального округа до 2020 года: Распоряжение Правительства РФ от 05.09.2011 N 1538-p. - Режим доступа: http:// economy.krasnodar.ru/strategic-planning/files/.

8. Суханова И.Ф., Юркова М.С. Проблемы и перспективы повышения инвестиционной привлекательности российского АПК // Аграрный научный журнал. - 2012. - № 7. - С. 98-103.

9. Турыгин О.М. Эффективность использования инвестиционных ресурсов российской экономики // Экономика региона. - 2014. - №-4. - С. 254-260.

10. Управление Федеральной службы государственной статистики по Краснодарскому краю и Республике Адыгея. - Режим доступа: http://krsdstat. gks.ru/.

11. Четошникова Л.А., Пазин А.В. Особенности и тенденции функционирования инвестиционной сферы Краснодарского края // Аграрный научный журнал. - 2015. - № 2. - С. 96-100.

Четошникова Любовь Александровна, канд. экон. наук, доиент, зав. кафедрой «Экономика, финансы и менеджмент», Новороссийский филиал Финансового университета при Правительстве РФ. Россия.

353907, г. Новороссийск, ул. Видова, д. 56.

Тел.: + 7 (8617) 21-15-98; e-mail:309460@mail.ru.

Ключевые слова: государственная поддержка отрасли; территориально-производственные кластеры; кластерный анализ; программно-целевое управление; инвестиционная деятельность.

\section{PROGRAM-TARGETED SUPPORT OF CLUSTER INITIATIVES IN THE AREA OF THE REGION}

Chertoshnikova Lyubov Aleksandrovna, Candidate of Economic Sciences, Associate Professor, Head of the chair "Economics, Finance and Management", Novorossiysk Branch of the Financial University under the Government of the Russian Federation, Russia.

Keywords: state support for the sector; territorial-production clusters; cluster analysis; targeted management; investment activities.

The article is devoted to the study of program-targeted support for cluster ini-tiatives in one of the priority areas of development of specialization of the economy of the Krasnodar region - the agro-industrial complex. It is shown that the development potential of the agro-industrial complex of the region is determined by its powerful agro-industrial potential. A significant reserve of activization of investment activity is laid in cluster formations. The problems of development of forming clusters in the sphere of the agro-industrial complex are identified and directions for the develop-ment of clusterization processes are determined. 